\title{
Managing Information for The Organizational Goal: Relationship and Function
}

\author{
${ }^{1}$ Tengku Adil Tengku Izhar, ${ }^{2}$ Torab Torabi \\ ${ }^{1}$ Universiti Teknologi MARA, UiTM Selangor, Malaysia \\ ${ }^{2}$ La Trobe University, Victoria, Australia
}

\begin{abstract}
Data is important to assist organization with decision-making in order to achieve the organizational goals. However, the trustworthiness of data is questioned because of the vast amount of data produced. This paper proposes an approach to utilize information from operational data to support the organizational goal. The challenge is to convert this data into meaningful information. This is critical for all enterprises to remain competitive. The aim of this paper is to propose a model to emphasize the dependency relationship involve between the variables such as organizational goal, sub-goals, actions, data input and data output. The relationship is important to assist the development of data measurement, data analysis and data modeling to measure the level of the organizational goals achievement. The contribution of this paper may serve as a first step to understand the dependency relationship between data and organizational goals to utilize meaningful information for efficient decisionmaking.
\end{abstract}

\section{Introduction}

Data is very important in every organization as a backbone for organization process and performance [1], [2]. Therefore, the success of an organization depends on the effective usage and management of internal and external data. In order to ensure the transformation of data, entire process of the organization needs to be understood. Organization has to make sure that every data created is alignment with their organizational goals. Organization needs to ensure the quality of it transformation in order to achieve the goals. Organization must have the ability to identify, create, store and measure the data. This data is stored in a data storage such database. However, this data is very large and not all data is valuable even the development of technology is improved.

Even though the organizations have a vast amount of data but at the same time, they do not have the data that they really need. Thus, the trustworthiness of organization data in relation to meeting the organizational goals is questioned and it poses an issue that how optimally the selected data may be used for better decision-making and fully achieving the organizational goals. Data is the most important organizational resource and it is important to identify the relevance data for the achievement of the organizational goals. At the same time, we suggest that organizational data is important as information and knowledge in every decision-making process. Therefore, it is important to understand the relationship between organizational data and organizational goals.

As an attempt to utilize the quality of data from vast amount of data, the aim of this paper is to develop a measurement approach based on the dependency relationship for different variables such as organizational goal, sub-goals, action, data input and data output. Every stage of organization process will be defined for the organizational goals model. This is important in order identify the possible relationship between data and organizational goals.

The remainder of this paper is organized as follows. Section 2 is literature review. In Section 3, we discuss the organizational model. Section 4 discusses the dependency relationship model between data and organizational goals. Section 5 is a conclusion.

\section{Literature Review}

Organizational goals can be defined as an organization main target. It is the higher and important achievement target in every organization and it consists the process to achieve the aim of the organization. In order to achieve the organization goal, it is important to understand the organizational goals structure. The structure of the organization is important to develop the efficiency and flexibility of the organization to cope with unpredictable [3]. For example organization structure is develop to achieve the performance of the organization [4], [5] or goal 
structure is develop to achieve the performance of goal [6], [7], [8]. The example shows a number of studies look at the organization structure toward the performance. This is because organization performance depends on the organization structure. Same with goal structure and goal performance, where organization goal depends on goal structure toward goal performance. There are number of organization goal studies that focus on the performance such as system performance [9], [10], goal performance [6], [7], [11] and organization performance [3], [4], [5], [8]. It is important to identify the entire organization modelling process as an effort to look at the organization performance and goal performance. However, the process can be very large and it is very difficult to evaluate organizational data as an effort to achieve the organizational goals. Compare to the previous study, we propose the organization model in the context of the organization goals.

Studies on organizational goals have been carried out since the early 1970s and 1980s in the context of business organizations. England \& Lee [12] clarified that the outcomes and understandings of such examinations have a tendency to be conflicting. The debate over social, economy, and organization issues connected with organization size will keep on attracting study and discussion in the years ahead. Commonly, business analysts tend to bolster the thought that larger organizations will bring about lower costs, larger amounts of productivity, and higher benefit levels up to some basic size of size.

Freeland \& Baker [13] recognized the confinements of a study on goal partitioning in a progressive organization. Constrained models exist to inspect the impacts of the diverse sorts of investment and good examples in objective setting in connection to goals acknowledgment, goals fulfillment, and execution. Campion \& Lord [14] recognized that little research has been coordinated at clarifying goals setting or at incorporating goals with other motivational speculations. The authors talked about goals structure and the relationship amongst goals and consequent execution. They inferred that goal setting ought to be seen as a dynamic procedure. Dillard [11] pondered the confinements of the goal expectancy model in an accounting organization.

Salerno [3] proposed a methodology and designed rules for organizational structures so they can rapidly be reconfigured to cope with unpredictable situations. The goal structure in a capricious circumstance is critical, and it demonstrates the relationship between the organizational goals and the organization's performance. Organizational structure is created with a specific plan to improve the performance of the organizations [11], [12], [13], [15]. The goal structure might be produced to strengthen the accomplishment of the goals [10], [13]. This is because an organization's performance depends on the organizational structure. Similarly, the organizational goals depend on the goal structure in relation to the goal performance.

Most of the recent studies on organizational goals incorporated system performance [9], [10], goal performance [6], [7], [11] and organizational performance [3] [4], [5], [8]. Performance is very important for the organization in order for it to achieve its goals. Therefore, it is important to identify the gaps in the previous studies in order to look at organizational goal performance. Recent studies also incorporated the organizational setting where the relationship between the organizational setting and performance was developed. Therefore, the relationship between the organizational setting and performance is important in relation to the organizational goals.

There are limited studies on the evaluation of organizational goals, especially in terms of evaluating the organizational data. Most studies on organizational goals focus on organizational performance, setting and behaviour [6], [16], [17]. There are several limitations in the existing literature in relation to structure and evaluation. In contrast to our model, we argue that it is important to develop a model to improve the understanding of the organizational goals structure. We also want to evaluate organizational data in relation to the organizational goals because there are limited studies on evaluating organizational data.

\section{Organizational Model}

In this paper, organizational model examines the level of the goals in the organization. For example, organization has principle goals. The goals upheld by sub-goals with a specific end goal to accomplish the main goals. With a specific end goal to accomplish the sub-objectives, a few actions distinguished. Actions characterize as the technique, arranging or action to accomplish the sub-goals. Actions depend on data so the organization needs to understand what sorts of data exist inside their organizations.

\subsection{Organizational Goals}

Goal is the higher accomplishment focus in the goal. It is a result that should be accomplished in light of the organization environment. Be that as it may, a few sub-goals are identified to accomplish the main goal and these sub-goals depend on the actions. Actions can be defined as training, planning or strategy and these actions rely on the organizational data. The idea behind this is to look at the measurement process of data aligning with the organization main goals. The degree of data process is the entrepreneur valuable information. Interpretation of this data is a new knowledge. 


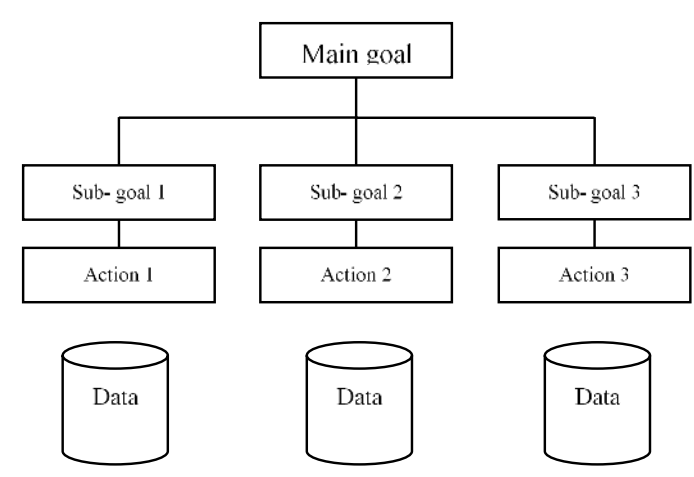

Figure 1. Goals relationship

Figure 1 shows the relationship between goals, sub-goals and action. In order to accomplish the main goal, a few sub-goals are identified to help the procedure of accomplishing the goals. Some organizations may have numerous sub-goals and it relies upon their organization surroundings. These sub-goals upheld by action, for example, preparing, methodologies or other action. In any case, these actions depend on data and it is critical to comprehend and distinguish the sort of data exist inside their organization.

In the proposed organization goals model, we expand the concept of action, task and activity. We define action depends on task and task is an activity involve in relation to organizational goals. In addition, action provides a systematic organizational plan, which must be followed to achieve the goals. In organization, in order to achieve the organizational goals, it consists of action. We characterize that action is performed by the organization to accomplish the goals. We utilize case from the university and library goal keeping in mind the end goal to extend the comprehension amongst action and tasks (see http://www.lib.latrobe.edu.au/about/vital plan.php). In the case, we take a look at La Trobe University Library's Strategic Plan for 2010 to 2015. In this arrangement, we can see the relationship between La Trobe University Library goal and action in connection to the La Trobe University's goal.

Sub-goal is defined as an out-come to achieve the organizational goals. Sub-goal is utilized as a platform by which to analyze the organization's performance in relation to the organizational goals. However, action is required to perform sub-goal. For example, the main goal is to Transform Student Lives Through Learning and the sub-goal is to Create Pathways for Underrepresented Students. Here, action to achieve this goal is 'to work with relevant university staff to develop programs to support under-prepared students' or 'review and further develop the library website in order to create more effective gateways for diverse client groups'.

Other example, if action is 'to work with relevant university staff to develop programs to support under- prepared students' then the possible task is to 'identify the student background in order to identify the most suitable program'. Based on the university and library goal, we can see the relationship between goal, subgoal, action and task. In our model, we suggest the usage of the organizational data as the important organizational resource in relation to the organizational goals.

\subsection{Data as An Important Organization Resource To The Organization Goals}

In order to perform the organization daily activity in relation to the organization goals, it relies on the organization data. In organizations, data is important as a strategic asset that can be leveraged into a competitive advantage. This is because many organization recognize the value and the need of the data within the organization as an effort to assist decision-making [1]. However, such data is too large though not all of this data is relevant to the organization goals. Even though information system and technology has been recognize to manage such data, the relevance of organization data in relation to the organizational goals always questionable.

Data give point of interest about particular needs. Information system such as databases execute data into informative information. User needs both data and information system to systematically provide a value to all users. In order to make decision, organization depends on the amount of data to make a fact based decision. Organization uses this data for analysis. Despite the fact that we live in association business data but almost no procedure has been work on information.

In organization, the usage of data is very important for manager to share. It is important for manager to receive relevant data in relation to the organizational goals. Recent study by Simsek et al. [2] discussed that sharing of important data and information can develop a knowledge for successful decision-making. It is very important for organization to create and generate new data and evaluate it for a better decision-making. Differences in generating new idea, information and knowledge will help in term of decision-making and will enable such team within organization to use relevant data for the organizational goals success.

\subsection{Process Development}

In this paper, we attempt to develop an approach to measure the quality of data as knowledge extraction toward decision-making. We attempt to look at the relationship between data and organization goal in order to develop a measurement approach. The approach is important in this case as a tool to identify the value of data to support the organization goal. Here, decision maker needs to make sure that all the decision is parallel with the organization goal. In 
every organization goals and objectives, several subobjectives is develop to support and to assist the organization to achieve the main goals and objectives. Every goal supported by organization actions such as planning and training. Thus, specific approach to achieve this goal is needed. On the other hand, the approach must support three basic functions. The basic functions are;

- Control: Ability to evaluate and control the resource.

- Communication: Well design toward internal and external performance.

- Improvement: Ability to improve and identify the gaps.

In order to attempt this approach, we try to focus on the early stage of data usage in an organization until the usage of data to support and assist the plan or action toward achieving the organization goal. Three simple steps need to be investigated. The process involves;

Step 1- Identification; identify the data type.

Step 2- Selection; select type of data.

Step 3- Quantification; quantify the data selected toward achieving the goal. Involve the measurement approach toward organization goal.

Simple measurement development process is developed to support the process. This process helped our approach to be specified and selection of the data become more systematic. In order to assist our model development process, we adopted the process applied by Serrano et al. [15]. However, compare to them, our application focus on every steps of data step rather than software measurement. Below show the process steps.

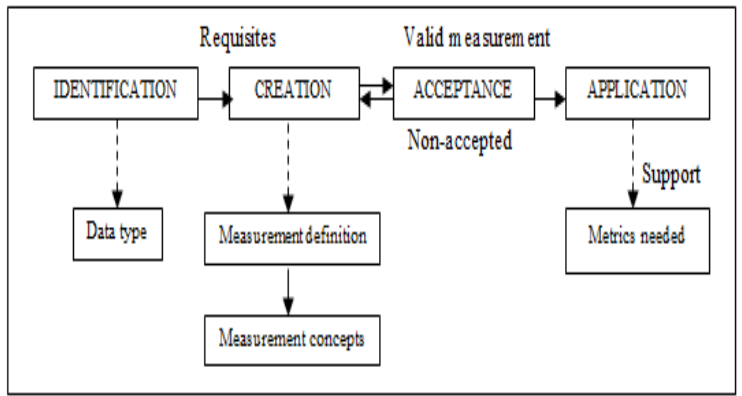

Figure 2. Measurement development process

Identification: Identify the data to measure. Future measurement rely on the data exist within the organization. In this context, data needed is to support the organization goals.

Creation: Crucial phase of measurement development. The phase included two important sub- processes which are measurement definition and measurement concepts.

- Definition: Understand the characteristic of measurement by defining several variable to show the overall relationship.

- Concepts: To test the relationship among the variables.

Acceptance: The concept is valid and can be tested. Application: The measurement tested to support the metrics needed.

The process assists the relationship involve between data selection and this process or flow is very important to make sure the relationship development of data can be applied.

\section{Dependency Relationship Between Data and Organization Goals}

The relationship in this research attempts to measure data to achieve the organization goals. The relationship runs as follows. Organization relies on data in order to run the entire organization so organization concepts, organization process and data process are defined. This data need to be measure in order to identify the quality of data. The process involved metrics approach so metrics concepts and data concepts are defined.

\subsection{Organizational Aspects}

Understanding the concept assist the overall process in term of achieving the organization main objective. Organization need to be clarified.

4.1.1. Definition 1: Organization Social group of people work in one scope of activity to achieve some develop objective. This group of people will distribute task toward implementing the develop activity.

4.1.2. Definition 2: Organization entrepreneur Group of people or a single person that directly associated with profit-making business undertaking.

Entrepreneurs in organization are recognized as the uncertainty and tight resource constraint by individual initiative and effort. This mean large organization need to develop an internal culture that allows their staff to be more initiative even though it tends to be more on experience initiative.

4.1.1. Definition 3: Organizational goals An outcome that organization developed to achieves in some particular period of time. The successful of organization plan and activity need to be parallel to the organization objective. The objective state 
precisely what the organization should be. Therefore, organization objective must be:

- Precise: To achieve the goals, the process statement must be exactly as state in the objective.

- Timeliness: Have a time frame to achieve the goals.

- Attainment: The goals can be achieved.

4.1.1. Definition 4: Organization action An outcome plan and activity that organization prepares to achieve the organizational goals. The successful organizational goals rely on the successful implementation of organization action. Therefore, organization action must be:

- Flexible: Action can adopt when the environment changes

- Consistent: Always referring to the objective

- Timeliness: Have time frame to perform

4.1.1. Definition 5: Organization requirement Design of what must be accomplished in order to achieve some target. In organization, organizational goals and organization action are important in order to accomplish the organization requirement. The requirement to accomplish the target is organization main goal. Let's denote that precise, timeliness and attainment as $P_{\text {recise }}, T_{\text {imeliness }}$ and $A_{\text {ttainment }}$ and flexible, consistent and timeliness as $F_{\text {lexible, }}, C_{\text {onsistent }}$ and $T_{\text {imeliness. }}$

The above may be written as

$$
\text { OrgReq: (OrgGoal)(OrgAct) }
$$

so,

$$
\begin{gathered}
\text { OrgReq: }\left(P_{\text {recise }}, T_{\text {imeliness, }} A_{\text {ttainment }}\right)\left(F_{\text {lexible }},\right. \\
\left.C_{\text {onsistent }}, T_{\text {imeliness }}\right)
\end{gathered}
$$

where OrgGoal and OrgAct is a variable for OrgReq which $P_{\text {recise, }} T_{\text {imeliness }}$ and $A_{\text {ttainment }}$ are the characteristics of OrgGoal and $F_{\text {lexible, }}, C_{\text {onsistent }}$ and $T_{\text {imeliness }}$ are the characteristics of OrgAct.

Example 1: In one organization, goal is an achievement target. It is an out-come that based on the organization environment. Main goals are supported with several sub-goals. For instance, in an organization, they have several sub departments and these sub departments has their goals in order to achieve the organizational goals. However, these subgoals depend on action such strategy, planning or training. In this case, action relies on data. So it is important for organization to identify and analyse the data.

\subsection{Metrics}

Metrics are designed to address organization process, which includes organizational goals and to assist the decision-making process. Therefore, metric must be clarified.

4.2.1. Definition 6: Metrics A verifiable used to measure both quantitative and qualitative. As a volume of data increase, metrics provide data refinement.

4.2.2. Definition 7: Metrics requirement Metric design of what need to be accomplished during the metrics process. Specific team attempts to identify the needs toward organizational goals achievement.

- Verifiable: Set of data that been agreed for converting process into measure.

- Measure: Characteristics in a numerical or nominal form.

4.2.3. Definition 8: Metrics analysis Requirement must be fulfilled.

- Control: Metrics enable to evaluate and control the source they are measures.

- Communication: Communicate externally and internally for the purpose of control.

- Improvement: Identify gaps for improvement.

Let denote that metrics requirement clarify as verifiable and measure as $V_{\text {erifiable }}$ and $M_{\text {easure }}$,

$$
\text { MetReq: }\left(V_{\text {erifiable }}, M_{\text {easure }}\right)
$$

and denote control, communication and improvement as $C_{\text {ontrol }}, C_{\text {ommunication }}$ and $I_{\text {mprovement }}$.

$$
\text { MetAna: ( } \left.C_{\text {ontrol}}, C_{\text {ommunication, }} I_{\text {mprovement }}\right)
$$

Therefore, above may also be written as

$$
\text { Met: (MetReq)(MetAna) }
$$

so,

$$
\text { Met: }\left(V_{\text {erifiable }}, M_{\text {easure }}\right)\left(C_{\text {ontrol }}, C_{\text {ommunication }}, I_{\text {mprovement }}\right)
$$

where MetReq and MetAna are the variables of Met which $V_{\text {erifiable }}$ and $M_{\text {easure }}$ are the characteristics for MetReq and $C_{\text {ontrol, }} C_{\text {ommunication }}$ and $I_{\text {mprovement }}$ are the characteristics for MetAna.

Example 2: Organization data needs to be measure and analyse in order to support the future usage of the data. One example of good metrics approach to support the data usage is Goal Question Metrics 
(GQM) [18]. However, this approach focuses on software development rather than data measurement. The concepts of GQM shows the systematic approach as it supports qualitative and quantitative analysis and the basic concepts of this approach can generalized to set up an organization measurement program even the development of this metric approach was focused more on software development

\subsection{Data Concepts}

Organization relies on data in every aspect of their actions. It is important for organization to identify, create, store and analyse this data. Data must be clarified.

4.3.1. Definition 9: Data Raw material such number or image. Organization relies on this data toward organizational goals. Specific team use data and convert it into valuable information.

4.3.2. Definition 10: Quality data Data must parallel with organization needs. Data in organization need to be subject-oriented such component of subject matter and improve the effective in responding to queries. Data must be:

- Complete: Complete present of the corresponding data records. Data completeness refers to the lack of needed fields.

- Accurate: Data is correct and set a context for further analysis.

- Current: Data is up to date to organization need.

Let denote that complete, accurate and current as $C_{\text {omplete }} A_{\text {ccurate }}$ and $C_{\text {urrent }}$. Thus

Data: $(Q D)$

So,

$$
\text { Data: ( } \left.C_{\text {omplete }}, A_{\text {ccurate }}, C_{\text {urrent }}\right)
$$

where data must be quality to support future need and performance. Data must be $C_{\text {omplete }}, A_{\text {ccurate }}$ and $C_{\text {urrent }}$ to considered quality.

Example 3: In order to improve organization performance, organization rely on data from previous activity. For example, sales manager require data on sales from last six months in order to come out with the plan toward future sales. Here, data present in form of reports or statistics and this data can assist manager to set a new goal.

\subsection{Organizational Process}

Organization process ( rrg $_{\text {process }}$ ) can be partitioned into several processes. However, organization process can be very large so in this paper, the focus of organization process is on their data existed. The algorithms are defined based on the organization goals and to shows the entire relationship of the organization goals rather than looking at the relationship between business side and data side [19]. Our approach is to look at the organization data flow and the impact of data toward organization goals. Our approach also intended to look at the relationship between the organization goals.

4.4.1. Definition 11: Process input During processing, data involve called process input $\left(\mathrm{P}_{\mathrm{i}}\right)$, where $\rightarrow$ is an involvement process. So decide

$$
\operatorname{Org}_{\text {process }} \rightarrow \mathrm{P}_{\mathrm{i}}
$$

4.4.2. Definition 12: Process output Every process generates output, so decide organization process involves process output $\left(\mathrm{P}_{\mathrm{o}}\right)$ where $\rightarrow$ also is an involvement process.

\subsection{Organizational Process}

Data process ( $D_{\text {process }}$ ) can also be partitioned into several processes. Here, process shows the flow of data within the organization.

4.5.1. Definition 13: Data input Every stage of process involved data input. Every organization created data almost every day and this data is store in data storage such as database. So data process involves data input (IN).

$$
\mathrm{D}_{\text {process }} \rightarrow \mathrm{IN}
$$

4.5.2. Definition 14: Data output Process generated output. Data store in data storage need to be evaluated to make sure that the data is valuable for certain action. So, data process involve data output (OT)

$$
\mathrm{D}_{\text {process }} \rightarrow \mathrm{OT}
$$

Let, Org $_{\text {process }}=\mathrm{P}_{\mathrm{i}}, \mathrm{P}_{\mathrm{o}}$, where $\epsilon$ is a characteristic $x$ can find in $\mathrm{P}_{\mathrm{i}}$. For example $y$ is an output of $x$

$$
\operatorname{Org}_{\text {process }}=\left\{\operatorname{Org}_{\text {process }}(x, y) \mid x \in \mathrm{P}_{\mathrm{i}}, y \in \mathrm{P}_{\mathrm{o}}\right\} .
$$

Then organization process can summarize as

$$
\operatorname{Org}_{\text {process }}=\left\{\operatorname{Org}_{\text {process }}(\mathrm{IN}, \mathrm{OT}) \mid \mathrm{IN} \in \mathrm{P}_{\mathrm{i}}, \mathrm{OT} \in \mathrm{P}_{\mathrm{o}}\right\} .
$$

It shows the entire $O r g_{\text {process }}$ rely on $I N$ and $O T$. Here, $P_{i}$ rely on $I N$ and $P_{o}$ rely on $O T$. The process define as $y$ depend on $x$ and it concludes as $O T$ rely on IN.

Goal and action are the main requirement to achieve the develop target within the organization. Develop target is organization main goals. Here we define organization requirement as 


$$
\text { Org }_{\text {requirement: }}\left(\operatorname{Org}_{\text {goal }}\right)\left(\operatorname{Org}_{\text {actions }}\right)
$$

We assume organization requirement as

$$
\text { Org goal }=\left(\text { Sub } b_{\text {goals }}, A_{\text {ctions }}\right)
$$

Therefore, full relationship can be developed here as

$$
\begin{gathered}
\operatorname{Org}_{\text {goal }}=\left(\operatorname{Sub}_{\text {goals }}, A_{\text {ctions }}\right), \operatorname{Org}_{\text {process }}=\left\{\operatorname{Org}_{\text {process }}(I N,\right. \\
\text { OT } \left.) \mid I N \in P_{i}, \text { OT } \in P_{o}\right\} .
\end{gathered}
$$

Summarize as

so

$$
\begin{gathered}
\operatorname{Org}_{\text {goal }}=\left\{\operatorname{Org}_{\text {goal }}(x, y) \mid x \in \mathrm{A}_{\text {ctions }}, y \in \mathrm{Sub}_{\text {goals }}\right\} \\
\text { Org goal }=\left\{\operatorname{Org}_{\text {goal }}(\mathrm{IN}, \mathrm{OT}) \mid \mathrm{IN} \in \mathrm{A}_{\text {ctions }}, \mathrm{OT} \epsilon\right. \\
\left.\mathrm{Sub}_{\text {goals }}\right\} .
\end{gathered}
$$

It summarizes the entire relationship as $\mathrm{Org}_{\text {goal }}$ rely on $S u b_{\text {goals }}$ and $A_{\text {ctions. }}$ Organization relies on data to support achieving the goals. The relationship is defined, as $S u b_{\text {goals }}$ is an $O T$ of Act where $S u b_{\text {goals }}$ and $A_{\text {ctions }}$ are the requirement for $\operatorname{Org}_{\text {goal }}$.

Example 4: In organization, the concept required the organization to achieve the target goal (main goal). Main goals supported with several sub-goals $\left(S u b_{\text {goals }}\right)$ in order to achieve the main goal. However, the subgoals need to be well plan so that it can be achieved and action $\left(A_{\text {ctions }}\right)$ is required toward achieving the sub-goals toward the main goals. $A_{\text {ctions }}$ such as training, planning and strategy rely on the data. Top management must know the type of data exist within the organization. Vast amount of data is created almost every day and this data has been stored in data storage (database). This is data input (IN) and $A_{\text {ctions }}$ are important to support the sub-goals. Data need to be identified it value if it is useful or valuable enough toward the sub-goals and this is the output $(O T)$ of the data.

\subsection{Measurement Process}

Previous section discussed on the relationship between the variable which are $\mathrm{Org}_{\text {goal }}, \mathrm{Sub} b_{\text {goals }}, A_{\text {ctions }}$, data input $(I N)$ and data output $(O T)$. However, in order to support the data measurement and this relationship, the following approaches are applies. First we define Org process $_{\text {and overall relationship for }}$ Org goal. $_{\text {. }}$

In order to support the data over the measurement process, several aspects are discussed. The main variables here are data input and data output where $n$ is a number of variables. Therefore,

Data input $(\mathrm{IN})=\mathrm{x}_{1}, \mathrm{x}_{2} \ldots \mathrm{x}_{\mathrm{n}}$

Data output $(\mathrm{OT})=\mathrm{y}_{1}, \mathrm{y}_{2} \ldots \mathrm{y}_{\mathrm{n}}$ and $\rightarrow$ is involvement aspect

Data input $(\mathrm{IN}) \rightarrow$ Process Input $\left(\mathrm{P}_{\mathrm{i}}\right)$

Data output $(\mathrm{OT}) \rightarrow$ Process output $\left(\mathrm{P}_{\mathrm{o}}\right)$

where IN is $X$ and OT is $Y$. Here, we show the relationship as

$$
\begin{gathered}
\operatorname{Org}_{\text {process }}=\left\{\operatorname{Org}_{\text {process }}\left(x_{1} \ldots x_{n} \in \mathrm{P}_{\mathrm{i}}\right) \mid x\left(y_{1} \ldots y_{n} \in \mathrm{P}_{\mathrm{o}}\right)\right\} \\
\operatorname{Org}_{\text {process }}=\left\{\operatorname{Org}_{\text {process }}\left(\mathrm{IN} \in \mathrm{P}_{\mathrm{i}}\right) \mid \mathrm{OT} \in \mathrm{P}_{\mathrm{o}}\right\}
\end{gathered}
$$

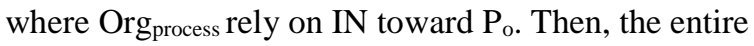
measurement process toward organization goal is

$$
\operatorname{Org}_{\text {goal }}=\left\{\operatorname{Org}_{\text {goal }}\left(\mathrm{IN} \in \mathrm{A}_{\text {ctions }}\right) \mid x\left(\mathrm{OT} \in \mathrm{Sub}_{\text {goals }}\right)\right\} .
$$

The explanation shows the relationship than involve the variable aspect toward organization goal. It is important for organization to identify the data that involve toward the goal and it involves process of data input and data output. Summarized the overall relationship as $\mathrm{Org}_{\text {goal }}$ is the process involving data input and data output toward $A_{\text {ction }}$ and $S u b_{\text {goals }}$ where $O T$ rely on $I N$. Here, IN, $A_{\text {ctions }}, O T$ and $S u b_{\text {goals }}$ are independent variables where $\mathrm{Org}_{\text {goal }}$ is dependent variable.

\section{Conclusion}

This paper discusses the overall concept data measurement for organizational goals model. Several variables such goals, sub-goals, action, data input and data output are defined. This paper also discusses the entire relationship of organization process toward data usage in relation to the organizational goals.

We define the variables as a basic structure for the measurement model. This paper limit to organization goals and data usage concept and we hope future action can focus on other aspects of the organization. The paper attempts to present some guidelines for goal structure development. In the next stage of our study, we intend to apply this approach and see the gap of this approach.

\section{References}

[1] N. S. A. Karim and R. Hussein, "Manager's perception of information management and role of information and knowledge manager: The Malaysian perspectives," International Journal of information Management, vol. 28, pp. 114-127, 2008.

[2] Z. Simsek, M. H. Lubatkin, J. F. Veiga, and R. N. Dino, "The role of an entrepreneurially alert information system in promoting corporate entrepreneurship.," Journal of Business Research., vol. 62, pp. 810-817, 2009. 
[3] M. S. Salerno, "Reconfigurable organisation to cope with unpredictable goals," International Journal Economics, vol. 122, pp. 419-428, 2009.

[4] P. C. Earley and R. Kanfer, "The influence of component participation and role models on goal acceptance, goal satisfaction and performance," Organizational Behavior and Human Decision Processes, vol. 36, pp. 378-390, 1985.

[5] O. Bouskila-Yam and A. N. Kluger, "Strength-based performance appraisal and goal setting," Human Resource Management Review, vol. 21, pp. 137-147, 2011.

[6] Y. Barlas and H. Yasarcan, "Goal setting, evaluation, learning and revision: A dynamic modeling approach," Evaluation and Program Planning, vol. 29, pp. 79-87, 2006.

[7] M. Sholihin, R. Pike, M. Mangena, and J. Li, "Goalsetting participation and goal commitment: Examining the mediating roles of procedural fairness and interpersonal trust in a UK financial services organisation," The British Accounting Review, vol. 43, pp. 135-146, 2011.

[8] M. Lepmets, T. McBride, and E. Ras, "Goal alignment in process improvement," The Journal of System and Software, vol. 85, pp. 1440-1452, 2012.

[9] S. Kang and H. E. Norton, "Nonprofit organizations' use of the World Wide Web: are they sufficiently fulfilling organizational goals," Public Relations Review, vol. 30, pp. 279-284, 2004.

[10] F. Ceresia, "A model of goal dynamic in technologybased organizations," Journal of Engineering and Technology Management, vol. 28, pp. 49-76, 2011.

[11] J. F. Dillard, "A longitudinal evaluation of an occupational goal-expectancy model in professional accounting organizations," Accounting, Organizations and Society, vol. 6, pp. 17-26, 1981.

[12] G. W. England and R. Lee, "Organization size as an influence on perceived organizational goals: A comparative study among American, Japanese, and Korean managers," Organizational Behavior and Human Performance, vol. 9, pp. 48-58, 1973.

[13] J. R. Freeland and N. R. Baker, "Goal partitioning in a hierarchical organization," Omega, vol. 3, pp. 673-688, 1975.

[14] M. A. Campion and R. G. Lord, "A control systems conceptualization of the goal-setting and changing process," Organizational Behavior and Human Performance, vol. 30, pp. 265-287, 1982.

[15] M. Serrano, J. Trujillo, C. Calero, and M. Piattini, "Metrics for data warehouse conceptual models understandability," Information and Software Technology, vol. 49, pp. 851-870, 2007.

[16] H. Tohidi, "Teamwork productivity \& effectiveness in an organization base on rewards, leadership, training, goals, wage, size, motivation, measurement and information technology," Precedia Computer Science vol. 3, pp. 1137 1146, 2011.
[17] J. Binswanger, "Dynamic decision making with feasibility goals: A procedural-rationality approach," Journal of Economic Behavior and Organization vol. 78, pp. 219-228, 2011

[18] V. R. Basili and D. M. Weiss, "A methodology for collecting valid software engineering data.," IEEE Transaction on Software Engineering, vol. 10, pp. 728-738, 1984.

[19] J.-L. Seng and T. C. Chen, "An analytic approach to select data mining for business decision," Expert Systems with Applications, vol. 37, pp. 8042-8057, 2010. 